\title{
How do we fight racism?
}

\section{Saiesha Anandabaskaran}

BDS4 Dental Student

$\mathrm{P}$ icture this. It is the early 1900 s and a dentist arrives at his new job. His employer takes one look at him and declares that the new dentist will destroy the practice in a day, solely due to the colour of his skin. This dentist was called Edward Tull-Warnock, and he is thought to be the first qualified black British dentist. ${ }^{1}$

It is now 2020, and the fight for racial equality is still relevant. Black lives still matter, and always will. This statement does not dismiss the importance of other races but instead addresses the systemic and institutional racism faced by black people. Although dental schools provide an inclusive environment, an improvement from the days of Tull-Warnock, nevertheless racial discrimination still occurs and more should be done to combat it. ${ }^{2}$

Let's start off with the political term BAME - Black, Asian and other Ethnic Minority groups. ${ }^{3}$ This term is often used to outline the diverse nature of different institutions. However, the danger of this word is that when grouping all minorities together, black people are often overlooked. For example, in 2016, 41,483 individuals were registered with the General Dental Council (GDC) and of this number $23 \%$ are BAME, but only $1 \%$ are black. ${ }^{4}$ These figures expose the need for widening participation schemes aimed at providing information on entry requirements prior to GCSEs, to improve the diversity of dental school applicants.

Recently, an Instagram post based on the British Medical Association's guidance was circulated by 35 dental and medical schools' societies nationwide. This highlighted how students can tackle racism in a clinical setting:

1. Seek support - Communicate with a trusted individual who will actively listen and help you e.g. a supervising clinician, wellbeing officer, or even a fellow student

2. Keep a record of the incident - Remember to include specific details such as the date, time, where and who was involved. This can be in any form, written down or recorded on your phone

3. Challenge the behaviour - It is important to do this in a non-confrontational manner whilst maintaining a professional attitude, and only do this if you feel able to. Explain to them how their words or actions have affected you and give them a chance to apologise and correct themselves

4. Report behaviour and complain - Familiarise yourself with the complaints procedure and make a formal complaint so that you can get the support you need, to not suffer alone

5. Be an ACTIVE bystander - Make sure you support the individual, for example by responding, 'that's not acceptable', and asking them if they are $o{ }^{5}$

But the thing is, this isn't just about dental students. It's about all of us. We all have to play our part. The current focus on the anti-racism movement should encourage all dental professional representative bodies to follow suit and create resources for both dental students and fully-qualified professionals alike. Whitgob et al. ${ }^{6}$ look at strategies to address discrimination against trainees in a clinical setting. This includes approaches that clinicians can employ to educate trainees to deal with such events. Some strategies mentioned include:

$\rightarrow$ Racial harassment case discussions using real or simulated scenarios to create discussion between students

$\rightarrow$ Addressing cultural attitudes and unconscious bias - this enables students to address their own biases and cultural beliefs to make sure that these do not affect treating patients from different backgrounds. Patel et al. ${ }^{7}$ found that unconscious bias based on skin colour was prevalent when dentists created treatment plans for teeth of uncertain prognosis. Hence, providing nonbiased training would improve patient care ${ }^{7}$

$\rightarrow$ Setting realistic expectations of racial mistreatment early on - this involves explaining that anyone can be discriminated against, allowing students to walk away if they cannot cope with the situation and need help from a clinician

$\rightarrow$ Educating staff - this includes training staff in both clinical and administrative roles on the NHS and Dental Schools' policies regarding racial discrimination. Thus, equipping them in deescalating any racial or discriminatory events whilst aiding the targeted individual. ${ }^{6}$

I - like many others - do not have all the answers and cannot provide all the solutions. But, in Black History Month, would like this to act as a conversation starter. The GDC and the British Dental Association have released statements addressing racism, which is a step in the right direction. ${ }^{8,9}$ Moving forward, Edward Tull-Warnock as a pioneer must be succeeded by many more black dentists. We are on the cusp of achieving something great, let's run with the momentum gained and never look back.

\section{References}

1. British Dental Association. A story of courage and achievement in early dentistry: Edward Tull-Warnock. 2018. Online information available at: https://bda.org/news-centre/blog/a-storyof-courage-and-achievement-in-early-dentistryedward-tull\#: :text=But\%20we\%20do\%20 know\%20about,1900s\%2C\%20and\%20tell\%20 his\%20story

2. Dentistry Online. Black Lives Matter- experiences from the dental profession. 2020. Online information available at: https://www.dentistry co.uk/2020/06/16/black-lives-matter-experiences/

3. McIntosh C. BAME [Internet]. Cambridge Advanced Learner's Dictionary \& Thesaurus. Cambridge: Cambridge University Press; 2013. Available from: https://dictionary.cambridge. org/dictionary/english/bame

4. Neville P. Exploring the ethnic diversity of UK dentistry. MedEdPublish 2018; 7: 55.

5. Racial harassment guidance for medical students. The British Medical Association, 2020. Available online at: https://www.bma.org.uk/adviceand-support/discrimination-and-harassment/ racial-harassment-in-medical-schools/ racial-harassment-guidance-for-medical-students

6. Whitgob E, Blankenburg R, Bogetz A. The Discriminatory Patient and Family. Academic Medicine. 2016; 91: S64-S69.

7. Patel N, Patel S, Cotti E, Bardini G, Mannocci F. Unconscious Racial Bias May Affect Dentists Clinical Decisions on Tooth Restorability: A Randomized Clinical Trial. JDR Clinical \& Translational Research. 2018; 4: 19-28.

8. British Dental Association. Black Lives Matter: Our commitment, our plan. 2020. Online information available at: https://www.bda.org/ news-centre/press-releases/Pages/Black-LivesMatter-Our-commitment-our-plan.aspx

9. General Dental Council. Racism and discriminationthe challenge for the GDC and dentistry. 2020. Online information available at: https:// www.gdc-uk.org/news-blogs/blog/detail/ blogs/2020/09/01/racism-and-discrimination-thechallenge-for-the-gdc-and-dentistry

https://doi.org/10.1038/s41404-020-0528-z 